\title{
Conversation: The Urges of Regional Language Dominance in India
}

\author{
Alok Kumar Suman \\ Research Scholar \\ Department of English \\ T.M. Bhagalpur University \\ Bhagalpur, India \\ suman.alok378@gmail.com
}

\begin{abstract}
This paper focuses on regional language dominance. India is a land of diverse languages. Its user follows the pattern of two or three language uses for their communication, i.e. one is 'national language', the second is 'mother tongue', and the next is a 'foreign language'. It is that no languages in India accepted as a national language like other countries as it has. We Indians are urging anyone language recognised as a national language. But the problem is to choose a lucky language. The answers are 'many'. Hindi may be renowned as our national language.
\end{abstract}

Keywords : Conversation, Dominance, Government, Language, National Education Policy (NEP-2020)

Introduction

All the states of India are urging for regional language implementation in the schools, the courts, the businesses, the offices, etc. Dominant medium, English, Hindi versus non- 
dominant medium, regional language, is challenging in Agriculture Education, Law Education, Medical Education, and Technological Education. Now the tension has grown between the central government and states. The fight against language is a colossal problem between us. Would language restrict us? Will it become a barrier for people to stay in the other state of India? What will take place? It is all about politics. But we endorse that language will never die if a single speaker is viable to that language. It must have to look at the 'National Education Policy' (NEP 2020) could settle such complications or not, or gender

will do itself. They will go for one national and one regional language and one foreign language. It might that in Bihar, like every state, belongs to the dominance of regional language is questionable in the upcoming date. Sanskrit is the basic foundation of India's culture, a renewable source of knowledge and science of the world. Gender can move towards the Sanskrit Language (called the soul of India) with the main two languages Hindi, English, and exercises extra languages.

\section{Language in India}

1. It divides India into 28 states and 8 union territories. Their official languages are Assamese, Bengali, Bodo, Dogri, English, Gujarati, Hindi, Kannada, Kashmiri, Konkani, Mai thili, Malayalam, Marathi, Meitei, Nepali, Oriya, Punjabi, Sanskrit, Santali, Sindhi, Tamil, Telugu, Urdu (total: 23, including 22 Eighth Schedule languages and an additional official language, English).

2. The Linguistic Survey of India (LSI) is a comprehensive survey of the languages of British India, describing 364 languages and dialects. The Survey was first proposed by George Abraham Grierson, a member of the Indian Civil Service and a linguist who attended the Seventh International Oriental Congress held at Vienna in September 1886. The survey continued for thirty years, with the last of the results being published in 1928 . 
3. The reports of Ethnologue, the number of individual languages recorded for India, 461 of these 447 are living, and 14 are extinct. Considering the varieties of language, users show unity in diversity.

4. There are 1,369 rationalised mother tongues. Near 400 in these languages are facing the threat of extinction.

5. Article 30 (1) of the Constitution of India provides a fundamental right to linguistic minorities to establish and administer educational institutes of their choice.

6. Article 351 provides a directive to the Union to promote the usage of Hindi across India.

7. Spanish, English, Hindi, and Arabic are the most widely spoken languages by over $40 \%$ of people worldwide when only first-language considered.

8. There are 9 states of 'Hindi Belt', Bihar, Chhattisgarh, Delhi, Haryana, Jharkhand, Madhya-Pradesh, Rajasthan, Uttar-Pradesh, and Uttarakhand. Its native speakers are about 528 million (2011). The media and the cinema are the biggest resources in spreading the language.

9. India is a Tricolour nation. In this sense, know her as a Tri-language country, Hindi, English, \& Regional language.

\section{Education Policies}

1. The National Policy on Education (NPE-1968) was prepared to improve the quality of education in the country and focused on providing education facilities to all the citizens of the nation. The policy has been reviewed in subsequent years.

2. Salient features of NEP 2020: The policy aims to universalise the pre-primary education by 2030 and provide foundational literacy for all by 2030. It proposes a new Curricular and Pedagogical Structure, with a $5+3+3+4$ design right to education covering 
the children in the age group 3-18 years. First, 5 years $=3$ years of Pre Primary, classes $1 \&$ 2, mother language and mathematics study, next 3 years $=$ Preparatory Stage, classes 3 to 5 , focus on writing skills, Middle School 3 years = classes 6 to 8 , focus on the vocational course and student entrepreneurship, Senior School 4 years = classes 9 to 12 is the multipledisciplinary education. The policy calls for all higher education institutions to "evolve" into one of three types of multidisciplinary institutions: research universities, teaching universities, and colleges. It also calls for building research capacities at all institutions and the establishment of a National Research Foundation.

3. The three-language choices by children, at least two of the three languages are native to India. This is an enormous task to teach in the unavailability of specialised teachers. The student's interests are keys. It is good that job opportunities will increase in education but the chances of conflict because every State holds major regional language demand. The Education Ministry has to solve these clashes in every state of India.

4. A single regulatory for higher institutions, multiple-entry-exit system in degree courses that is students can leave with a certificate after one year, diploma after two years, degree after three and degree with research after four years, and discontinuation of the Master of Philosophy (MPhil) programs, low stakes board exams, common entrance exams for universities are among the highlights of the new National Education Policy.

5. The education system runs in favour of job seekers, job givers, quality, and quantity of education. The Government School of the States hardly follows subject wise teachers, the discipline, the rules, and the infrastructure. Teachers were complaining about the involvement in extra activities other than teaching, i.e. Election duty, survey duty, Mid day Meal, and school's political activities, etc. 
6. Addressing the finale of 'Smart India Hackathon', the Prime Minister said that the new Education Policy 2020 emphasises inter-subject study, which will ensure that the student who wants to learn has full attention. You are on it.

7. The policy focuses on flexibility. In this, the students have to choose no rigid formation of streams of arts, commerce, and science in schools. Students can take up whichever courses they want. In the Pre Primary teaching up to at least grade 5 to be in mother tongue/regional language that would compulsory, and all courses offered in two languages.

8. The efforts required over Discovery-Based, Discussion-Based, and Analysis-Based study to the child. And strengthen the policy of 'how to think' rather than 'what to think'.

\section{Conversation}

Mr. I am confused about which language we will talk.

Mrs. I will speak the same language in which you are talking every day, you have made a strange talk about it. Please clarify.

Mr. Every state is urging its regional language. It would be the national language. This is not desirable.

Mrs. It's true.

Mr. They are focusing on regional language as a venerable language, and a protest to Hindi. Mrs. Why this then?

Mr. Political speculate may be. But between it 'English' surfaced as a principal language since 1600 A.D., after British intruders reached to India.

Mrs. So, English should be our national language. 
Mr. No, but we can't escape English as a fundamental language. It is a universal language. People are communicating worldwide through a single common language, i.e. English. Each country is holding its own national language. They address the speech in their language.

Mrs. Our Prime Minister delivers the speech in Hindi, so our national language is Hindi. He uses the English language, Sanskrit language, and other regional languages too.

Mr. Yet, the States will decide the preference of the dominant language Hindi, English, or regional language.

Mrs. They can receive all the three languages in the course. Hindi and English may be obligatory for individuals as they are habituated, and the states' regional language per choice. Mr. It is a convenient idea. We have a concerning problem with the subject of Mathematics, law, science, medicinal, marketing, social science, and linguistics, etc, that oftenest the textbooks are in the English language. Translating it into regional language is a challenge, for that only English is the option with us or will require a translator.

Mrs. Our Constitution, International courts, and computers, etc, are in English versions.

Mr. Why is Hindi not an international language?

Mrs. Because it is not spoken everywhere. I heard through the newspaper the Marathi language department of the Maharashtra government issued the particular state governmentuse Marathi in official communication. The state government also asked department heads to warn those who deliberately not using the Marathi language in official communication.

Ht INDIA Updated: Jul 01, 2020, 09:41 IST

Mr. Maharashtra has studied laws enacted by southern states of Tamil-Nadu, Telangana, Karnataka, and Kerala that made their languages mandatory in schools.

Mrs. 'No compulsory Hindi in Indian School after Tamil Nadu anger' (The Indian government has revised a controversial draft and bill to make Hindi a mandatory third language in schools across the country). 
BBC NEWS: 3 June 2019.

Mr. The Ministry of Human Resource Development (MHRD) said that no language is mandatory. The States can choose any three languages.

Mrs. The changed name of MHRD is the Ministry of Education. The language division will create the biggest problem. The States will divide lingual. Migrant people will have to learn that language to remain.

Mr. This will hurt the nation and formed inferiority among the immigrant and migrants people. Such type of culture adversely affects development.

Mrs. The worry will set up among the labourers and the visitors. For them, it will trouble to interact with locals.

Mr. Is the State unity more necessary over the draft of the National Education Policy?

Mrs. Yes, at least one language can be accepted, and this approach to every individual.

Mr The part of South and West prefers English as a common language, the Middle, the North, and the East part of India prefer Hindi.

Mrs. The state's administration is a sovereign State to regulate its citizens. But why is the government not taking any significant step about one national language teaching?

Mr. Our Prime Minister's dream is one nation, one language. Since coming to power in 2014, the BJP and its supporters embarked on their wanton campaign to privilege uniformity over unity.

Mrs. It would be.

Mr. I stayed near Ramakrishna Math, Hyderabad, Domalguda, Telangana 500 029, India for 6 months on rent. My room-honour communicates in Telugu. I didn't know how to speak Telugu? Again used sign language and at last, kept a translator.

Mrs. You could handle it. But this is not satisfactory to all language users. The three language practices can help. Hindi and English are the network language. 
Mr. For 'unique identification' Hindi can be selected as a national language. It's a pride for the nation. It's more than other language users.

Mrs. Aren't you considering the studies in only regional language will be beneficial for children?

Mr. No, we can only be common rather than personal.

Mrs. The holy book of the Vedas was composed in Sanskrit. Only Sanskrit readers can read its terminology and interpret the context. We aren't habituated. The translations possible in the other dialects are simple to interpret and use. Don't you expect?

Mr. Translations are essential for languages. It can use to explain the context. The stock of words and terms in any language usage is not sufficient. The concept is the same with distinct Letters and distinct Words. We are living in a foreign country using a translating machine or translating app or translator.

Mrs. It can't be without expertise.

Mr. Yes, but the pronouncement of a proper noun is the same all over the world's language. Mrs. Languages' indifference is oppression. Regional Languages' alienation can't be tolerated.

Mr. Of course, it can't be. But how can individual alienation in languages be tolerated for those who love their nation?

Mrs. Thus, what is its solution? Which will allow the right of language usage?

Mr. One language accepted as a national language, second as a universal language, and the rest is as a mother language. Individuals can use any of the languages.

Mrs. The languages Hindi and English would be implemented then there is no need for other languages to study.

Mr. To preserve our culture, folk tradition, and identity, etc. the study of regional language is remarkable. 
Mrs. It saves the records of our mother tongue, the national language, and the worldly language. Every state may open the 'State's Dialect School' and museum at their provincial University. All the scripts of languages are to keep digitalized and culture, songs, dance, craft, and film, etc.

Mr. That can deal with political only. The languages are advancing day by day through the books, the newspaper, the speech, the film industry, celebrity, political leaders, advertisement, migrant users, etc.

Mrs. The Constitution of India safeguards the regional language. But the linguistic majority dominates over the linguistic minority. Such languages are Hindi and English.

Mr. Minority's languages are the most spoken language. The courts can hear in the transcript form of any language.

Mrs. Sometimes a linguistic minority shows the backwardness of the people.

Mr. This backwardness can be determined only by learning the majority language. The affirmative step would be received by the government to sustain the regional languages and enhance the major languages.

Mrs. Yes, even we can't talk in the bulk language.

Mr. But the availability of a teacher who teaches all the subjects is found in a bundle.

Mrs. what do you say about the NEP 2020? The draft submitted by K Kasturirangan.

Mr. The National Policy on Education (NPE) is a policy planned by the Government of India to promote education amongst India's people. The policy covers elementary education to higher education in both rural and urban. It is the third NEP promulgated by Prime Minister Narendra Modi on 29th July 2020. The draft aims to transform the intent and content of education sector, focuses on shifting the burden of school bag to the boon of learning, integrating 'local' with 'global' making the youth 'future ready' while focussing on national goals, ensures that students become global citizens while remaining connected to their roots, 
shift focus from 'what to think' to 'how to think', higher education institutions need to be empowered through autonomy, and there is great emphasis on teacher training in National Education Policy.

Mrs. The draft talks about regional or mother language learning at the elementary level.

Mr. Yes! It is in the hands of the State Government, which language is as its mother language? The Multi-Language Teaching and child quality education system can burden for any Government. It may come with pejorative results because of poor handling of the system and the free education policy. In that, the door of many vacancies opens.

Mrs. Free education policy will benefit the gender.

Mr. The budget, corruption, and vacancies in education affect the economy of India.

Mrs. Do you say that free education and allotment of teachers will affect the economy?

Mr. Yes, for quality education, the 'Pay for Education' policy achieves pre-supposition to teach multi-languages.

Mrs. Don't think so.

Mr. The condition of education is not good. Free education is not working. The Corruption hunters are very much, and this might not stop because of multiple-powers. As per opinion, the Government School goes for semi-privatizations, no free education, i.e. 'no pay, no school', and teaching with a fixed nominal fee, 'Guru-Dakshina'.

Mrs. Children learn only one regional language but think of other dialects. What this means to Educate, Expand, and Expense over language. It is the 'Waste of time in so many language learning, without interest'.

Mr. It is important up to 5th standard regional language would be taught and from the 6th Standard onwards as per gender's choice. They have credit given to choose from the options. Gender can go according to the pattern of competitive exams and for further study. 
Mrs. India has a bundle of linguistic differences. She has so many languages, dialects, and even has distinct accents.

Mr. We recognise the demand for language teaching and dialects teaching are vigorous.

Mrs. It needs to focus on science teaching, technology teaching rather than language teaching.

Mr. Language teaching culture is like the entry-exit system and picking popcorn. Not a single language became the medium of instruction till 21 Century India. The history said that the biggest transformation in the language been arranged into chronicle ways, from the Sanskrit era to the Hindi and the English era.

Mrs. The performance of children who study in non-English languages as the medium of instruction is better.

Mr. It is only to say, impossible to get into the same environment everywhere, basically in India. West Bengal and the South States implemented this many years back. But in the states; Bihar, Bangalore, Assam, Uttar-Pradesh, Rajasthan, etc have several dialects as mother languages that demand to dominate.

Mrs. Students think like 'woo'! It is Hindi, my subject. They give little time to this paper.

Mr. Yes! Sanskrit and Hindi, out of it, gender has a choice of the preferred language teaching. Mrs. Culture is progressive; it has script, music, dance, dress, food, etc.

Mr. Yes! But for transferable job seekers family face much problem than native settlers. Mrs. The ratio of the particular language choice per gender will decide the next suggestions. Mr. Child's education might be in a domestic atmosphere but what about Science education? How can a child receive a Science atmosphere?

Mrs. Science education will be easy in the planetary atmospheres. The teacher will use which language in all the periods of various recommended studies? Is the interpretation of English 
lessons in the regional language or national language or English? It depends upon the principle of a teacher.

Mr. The understanding among children and teachers emerges when discipline occurs in them. It grows from parents, society, and the digital world. The domestic environment avoids discipline.

Mrs. the Education policy needs a change of School Management and establish a friendly environment among the parents, the teachers, and the students. Further, the culture and the pattern of studies of both the Government and Private Institutions for the regional language recorded under consideration.

Mr. We have to watch how policies run.

Mrs. The parents have to more careful and cooperative about child education, their interest in the learning of the dominant language.

Mr. Every hypothesis has a result that suggested method in favour or not favouring. But water finds its own path. Gender is trapped systematically in the dominant language learning. Mrs. The policy offers a correspondence study of language paper for the value in all the competitive exams.

Mr. Here to mention is the sentiment of a single Indian ethos doesn't matter. Need for implementation of profitable laws, too.

Mrs. Division of dialects means a division of culture, religion, land, and individual. This we call it 'Democracy'. Class of dialects means its culture, and freedom means its dominance.

Merits of language dominance

- $\quad$ Language dominance means the privilege of that language which widely spoken or is in the written form.

- It connects many people and rise dignity. 
- $\quad$ Creating space for other activities.

- It avoids the language burden and serves as a medium of language among the distinct population.

- It applies to development in all areas.

- It unites our expressions and binding them into a category.

- It is convenient for teaching, communicating, and business. For example, when you go to another State for treatment in the hospital, and you know only your regional language. Then have newer problems to handle this situation.

- $\quad$ Language interacts with us, interprets us, and ties us.

- It promotes curiosity and imagination instead of herd mentality.

- It implements one language nation policy.

Demerits of language dominance

- The dominance of another language may create problems that the languages want to be dominant.

- $\quad$ Risk of extinction of other languages.

- It may divide the speakers into the categories and classes.

- Gender identity is easy to recognise.

- It will affect the speakers of other languages.

- $\quad$ It can provide interruptions and errors.

- Multi-languages are like an alien. In a tribal community or a rural community, people usually speak in the mother language, rather than making use of link language, because of the illiteracy and fear. How communication might be when link/dominant language is not available? Talking and teaching in the regional languages can be possible, but better to interact with the native speakers to learn that language. Or either keep quiet. 
- It will directly attack cultural pride. Then what about the country's pride?

- It has a language problem. Among the Devanagari speakers and other speakers like Dravidian speakers, Austroasiatic speakers, Sino-Tibetan speakers, Tai-Kadai speakers, Great Andamanese languages, etc. They belong to the Indo-Aryan families.

- $\quad$ The language use in the different regions are based on - (1) same/different words (2) same/different meaning of the words (3) same/different tone/accents of the words possibly shown in the table: 1

\begin{tabular}{|c|c|c|c|}
\hline & languages & words & Sentences \\
\hline & Hindi & हूँ (hoon) & मैं तुमसे प्यार करता हूँ \\
\hline & English & I am & I love you \\
\hline & Angika & छिग़ै (chhiyai) & हम्में तोरा से प्यार करे छिधै (hamen tora se pyaar kare chhiyai) \\
\hline & Bengla & আমি (Āmi) & আমি তোমায় ভালোবাসি (Āmi tōmāỳa bhālōbāsi) \\
\hline & Maithili & छी (Chī) & हम अहाँ स प्रेम कोरेछी ham ahaan sa prem korechhee \\
\hline & Gujrati & છુ (Chu) & હું તને પ્રેમ કરું છુ (Humં tanē prēma karum chu) \\
\hline & Nepali & हो $(\mathrm{Ho})$ & म तिमीलाई माया गई्छु (Ma timīlā'ì māyā garchu) \\
\hline & Marathi & मी आहे ( $\mathrm{Mī}$ āhē) & मी तुझ्यावर प्रेम करतो (Mī tujhyāvara prēma) karatō, \\
\hline & Tamil & நான் (Nāñ) & நான் உன்னை நேசக்க றேன் (Nāñ unnai nēcikkirēn̄) \\
\hline 0 & Telugu & నేను (Nēnu) & నేను నిన్ను ప్రేమిస్తున్నాను (Nēnu ninnu prēmistunnānu) \\
\hline
\end{tabular}

Note: Here in the above table, only 10 distinct languages are noted. It is recognised that register of speeches among one another, the contrasts of languages among one another, and the use of blended language. Every language receives its different talk. 
- Error in the language use - Hindi: आप समझते हैं/ आप समझे/ आप बुझे। Angika: बुझे means in English; 'off', 'over', 'understand', etc. While the speaker speaking, they use a regional word in between, which means an error in the language. But, it is a culture of using borrowing words from the dominant language to the regional language.

- $\quad$ The language may create trouble, try to refrain from it, for example-Hindi: कृपया मुझे गुदा वाला मांस दें। English: please give me boneless meat. But in another region 'गुदा' means anus.

- Variation in the same language: Angika: 'कटीटा' and 'तनीटा', (meaning in Hindi: थोड़ा सा), there are two different words used in $3 \mathrm{~km}$ differences of place, with no change in the meaning.

Language conflict

- $\quad$ Article 343 (1); of the Constitution of India states, "The Official Language of the Union government shall be Hindi in Devanagari scripts". The Parliament decided the use of English for official was to cease 15 years after the constitution came into effect on 26 January 1965.

- There are conflicts over linguistic rights in India. The first major linguistic conflict, known as the Anti-Hindi agitations of Tamil Nadu, took place in Tamil Nadu against implementing Hindi as the official language of India.

- To express disapproval of imposing Hindi on its states' the government of Maharashtra made the state language Marathi mandatory in educational institutions of CBSE and ICSE through Class/Grade 10. The Government of India attempts to assuage these conflicts with various campaigns, coordinated by the Central Institute of Indian Languages, Mysore, the Department of Higher Education, Language Bureau, and the Ministry of Human Resource Development. 
- Government planned to make Hindi compulsory averted. But with more than half of these India's 1.2 billion people using another language as their mother tongue.

- Bihar is the land of various languages, such as Maithili speakers, Angika speakers, Bhojpuri speakers, Magahi speakers, and other language speakers. The clash with languages in Bihar is itself a serious matter. The demand to include 38 more languages in the 8th Schedule of the Constitution pending to approve is; Angika, Banjara, Bazika, Bhojpuri, Bhoti, Bhatia, Bundelkhand, Chhattisgarhi, Dhatki, English, Garhwali (Pahari), Gondi, Gujjar or Gujjari, Ho, KaachachHi, Kamtapuri, Karbi, Khasi, Kodava (Coorg), Kok, Barak, Kumaoni (Pahari), and Kurak. The other languages are; Lepcha, Limbu, Mizo (Lushai), Magahi, Mundari, Nagpuri, Nicobarese, Pahari (Himachali), Pali, Rajasthani, Sambalpuri or Kosali, Shaurseni (Prakrit), Siraiki, Tenyidi, and Tulu.

- The problem of language conflict is politically and socially. One side is the endangering of cultural pride and the other side of national pride. Which to save? Confusion!

\section{Conclusion}

The influence of language results in good or not, the language which shapes the content and sense may create strain and may assist you. As has 'English' a link language, but will not be involuntary, 'Sanskrit' and 'Hindi' as the national language, and the further privilege to the regional language. They act, not impose it over, but for country pride, it can resolve. Someone has twitted that Hindi is the national language of which nation? Imagi NATION! Language is a choice of Gender. 


\section{References}

Brass, Paul R. (2005). Language, Religion and Politics in North India. iUniverse. p. 129. ISBN 978-0-595-34394-2.

Keith Brown (ed.). (2005). Encyclopedia of Language and Linguistics (2 ed.). Elsevier. ISBN 0-08-044299-4.

Moseley, Christopher (10 March 2008). Encyclopedia of the World's Endangered Languages. Routledge. ISBN 978-1-135-79640-2.

\section{Web Source}

https://en.wikipedia.org/wiki/Constitution_of_India. Retrieved Dec 20, 2019.

https://en.wikipedia.org/wiki/Languages_of_India. Retrieved 12 March 2019

http://www.ethnologue.com/17/language/mai/

https://www.mhrd.gov.in/nep-new 